\title{
Indoor measurements of particulate matter during steak cooking under different conditions
}

\author{
M. Schiavon, E. C. Rada, M. Ragazzi \& D. Antolini \\ Department of Civil, Environmental and Mechanical Engineering, \\ University of Trento, Italy
}

\begin{abstract}
Few studies on domestic indoor air pollution have given quantitative information on the variation of the characteristics of the indoor source of particulate matter (PM). This paper is intended to contribute to the understanding of this phenomenon referring to beef-steak cooking by means of natural gas, which is expected to be a cleaner source of PM, especially compared with biomass. The origin of this paper is based on the variability of the power of the cooker in order to study the sustainability of natural gas from the point of view of the induced indoor human exposure to PM. Measurements were made by a GRIMM analyzer, able to measure 16 granulometric classes from 0.3 to $20 \mu \mathrm{m}$. Using the biggest cooker, the $\mathrm{PM}_{10}$ production gave results 3 times higher than the case with the smaller one, even if the appearance of the cooked steaks was the same. In particular, this increase is higher for the finest fractions of PM. It is clear that good ventilation is compulsory to reduce human exposure to this kind of source. Keywords: cooking, indoor air, natural gas, particulate matter.
\end{abstract}

\section{Introduction}

The presence of particulate matter (PM) in the ambient air has been a topic of interest for decades. Monitoring activities were performed in all the continents as demonstrated by the scientific literature [1-6]. Sites in low income [4], medium income [7] and high income [8] countries around the world were studied in order to generate data useful for the assessment of human exposure to PM. Even remote sites were investigated for a background comparison [9]. Some research zoomed from regional monitoring [10] to urban areas [11]. Other studies focused on specific mobile sources [12-14] on the finest fractions of PM [8], on the 
seasonal variability of the PM concentration values [15] and on the specific contribution of point sources [16].

All these studies allowed the development of prediction tools [17], but could not complete the generation of the necessary data for the assessment of human exposure. Indeed, in the literature, the role of particulate matter in indoor environments showed a growing interest. Particular attention was made to indoor concentrations in workplaces [11]. Recent studies focused on specific indoor environments as pizzerias [18], hospitals [19], schools [20], churches [21] and tunnels [22]. However, today it is well recognized that the role of domestic indoor exposure is not negligible: high PM values were found both in low income [23] and high income countries [24].

Only few researches on domestic indoor air pollution give quantitative information on the variation of the characteristics of the PM indoor source. This paper is intended to contribute to the understanding of this phenomenon, referring to a specific cooking activity performed under different conditions. The here studied source is natural gas, typically used for cooking in developed countries. In terms of PM emissions, this source is cleaner in comparison with the adoption of biomass, but particles are anyway generated during the cooking process, especially for baking, grilling, roasting and toasting [25]. In such cases, carbohydrates, fats and proteins undergo pyrolysis and aerosols are released into the environment.

In a previous research [26] it was demonstrated that the role of PM exposure in kitchen room could not be negligible: in that case study, exposure to PM in kitchen represented about one third of the daily exposure. The originality of the present paper is based on the variability of the power of the cooker. This aspect has not been analyzed in previous researches [27].

Since $\mathrm{PM}_{10}$ is not adequate for a complete vision of the human exposure to particulate matter, the instrument chosen for the experimental activities was an analyzer able to measure also lower granulometric classes.

\section{Material and methods}

The main tool used for the measurements is the GRIMM analyzer 1.108. This tool is similar to the one adopted in a recent research on indoor air pollution [23]. This instrumentation measures 16 granulometric classes from 0.3 to $20 \mu \mathrm{m}$ [26]. This tool allows assessing particulate matter with different diameter. The values taken into account in this paper for the developed case-study are $\mathrm{PM}_{10}, \mathrm{PM}_{2.5}$ and $\mathrm{PM}_{1.0}$.

The ambient-air to be analyzed is drawn into the unit via an internal volumecontrolled pump at a rate of 1.2 liters/minute. The sample passes through the sample cell, through the laser diode detector and is collected onto a $47-\mathrm{mm}$ filter. The entire sample can then be analyzed gravimetrically for verification of the reported aerosol mass. The pump also generates the necessary clean air, which is filtered and passes through the air regulator back into an optical chamber. This is to ensure that no dust contamination comes in contact with the laser-optic assembly. Data are also available via the built-in serial port. These data, 
available in intervals of every 6 seconds or every 60 seconds, can be transmitted to an external computer. The particle size analyzer/dust monitor determines the dust-concentration (counts/liter) through the optical-light-scattering method directly. It must be pointed out that this method is generally not used as the official one: the Environmental Agencies typically adopt gravimetric methods according to the present regulations. If we consider the aim of the present research, the used tool is suitable in order to obtain significant scientific results about PM generation varying the characteristics of an indoor source.

For the development of the present research, the GRIMM instrument was placed in the center of a selected kitchen, $2 \mathrm{~m}$ away from the stove location. This choice was made in order to simulate the exposure of people sitting at the table. The selected room is square-shaped, measuring $4.5 \mathrm{~m}$ on each side and with a $2.6 \mathrm{~m}$ height. The research concerned the cooking of beef-steaks, each weighing $200 \mathrm{~g}$. Neither oil, nor dressing was used. All the steaks were well-done.

Indoor measurements for each beef-steak were made. Three natural gas cookers, with different thermal powers, $1.65 \mathrm{~kW}, 2.3 \mathrm{~kW}$ and $3 \mathrm{~kW}$, were used. The stove was equipped with a hood filter for managing the exhaust gas. Its correct operation was checked. The lasting of the measurements was chosen taking into account the lasting of the cooking time. It took a few minutes to cook the steaks. The window of the kitchen was opened about 20 minutes after starting cooking.

Some outdoor measurements were also used in order to verify that outdoor PM concentrations did not influence indoor PM concentration during steak cooking. Some results from a previous study [25], here called "Steak 0", were also used for a comparison.

\section{Results and discussion}

The first steak, named "Steak 1", was cooked using the smaller cooker $(1.65 \mathrm{~kW})$. "Steak 2" was cooked using the medium one $(2.3 \mathrm{~kW})$ and "Steak 3" using the larger one $(3 \mathrm{~kW})$. In all cases humidity in the kitchen was not critical for the correct use of the GRIMM analyzer.

In Figure 1 the concentration of particulate matter due to the cooking of "Steak 1" is reported. The cooking time was 7 minutes. A clear lag between the starting of cooking and the detection of the increase of PM concentration can be seen. This aspect can be explained by the distance of the measurement location (on the table). From Figure 1, very high PM concentrations can be observed when diffusion was complete. In particular, the finest fraction $\left(\mathrm{PM}_{1.0}\right)$ reached values higher than $600 \mu \mathrm{g} \mathrm{m}^{-3}$. The window was kept open for 26 minutes after cooking was started. 


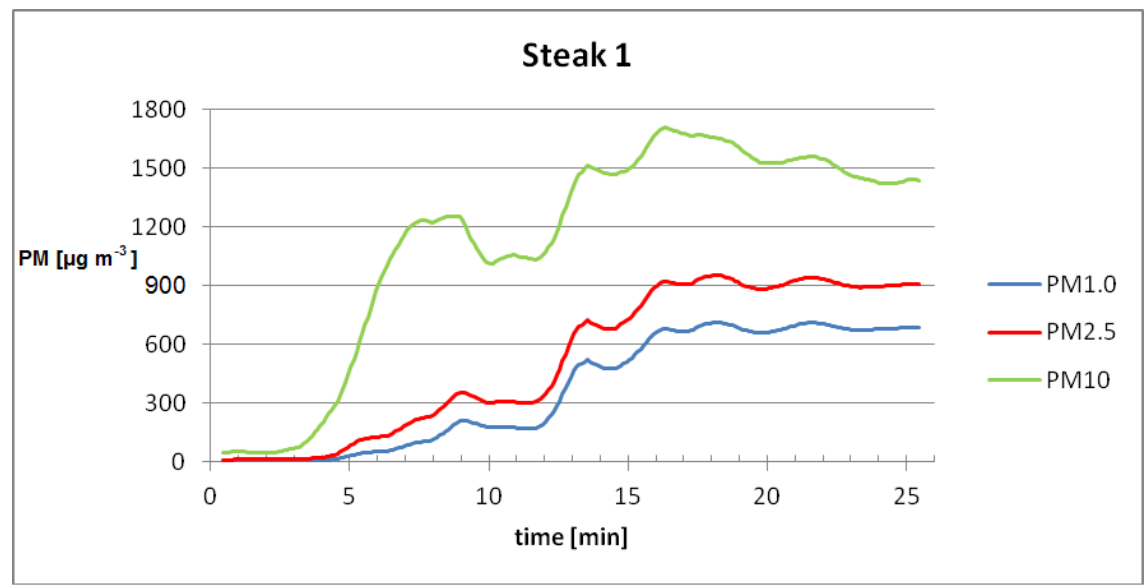

Figure 1: $\quad$ PM concentration during the cooking of "Steak 1".

In Figure 2 the PM concentration for "Steak 2" is reported. In this case the cooking time was 6 minutes (shorter than the first case, as expected). The effect of using a more powerful cooker is clear: $\mathrm{PM}_{1.0}$ concentrations reached values higher than $1,000 \mu \mathrm{g} \mathrm{m}^{-3}$. The higher concentrations detected can explain the shorter lag time between the starting of cooking and the detection of the increase of PM concentration. The window was kept open for 26 minutes after starting cooking.

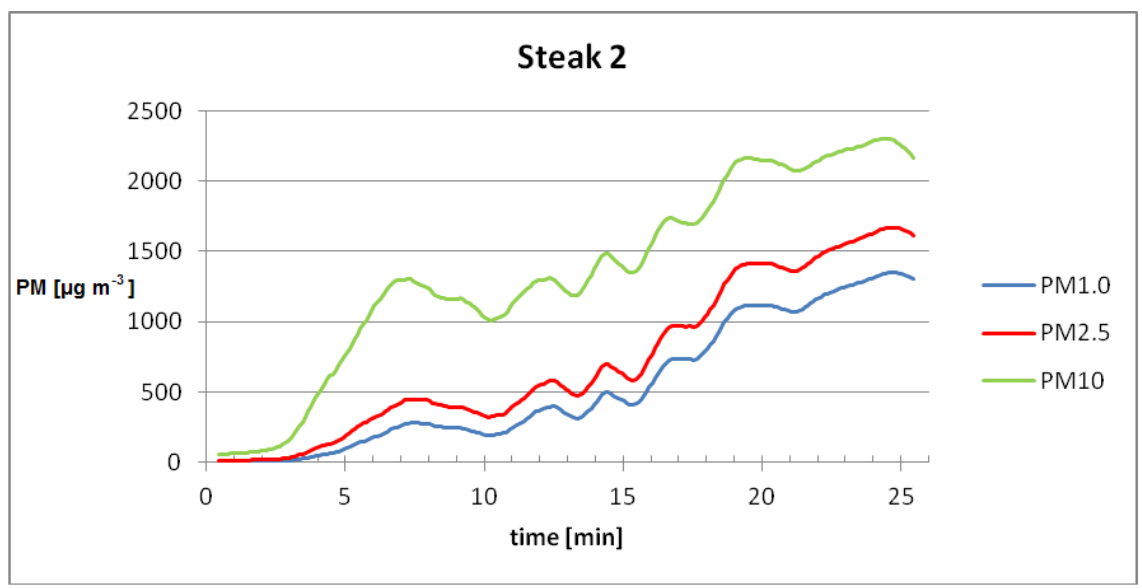

Figure 2: $\quad$ PM concentration during the cooking of "Steak 2".

Figure 3 shows the PM concentration for "Steak 3". In this third case, the cooking time was 5 minutes and the window was kept open for 22 minutes after starting cooking. As expected, cooking was quicker. In this case, $\mathrm{PM}_{1.0}$ concentrations reached values higher that $3,000 \mu \mathrm{g} \mathrm{m}^{-3}$. 


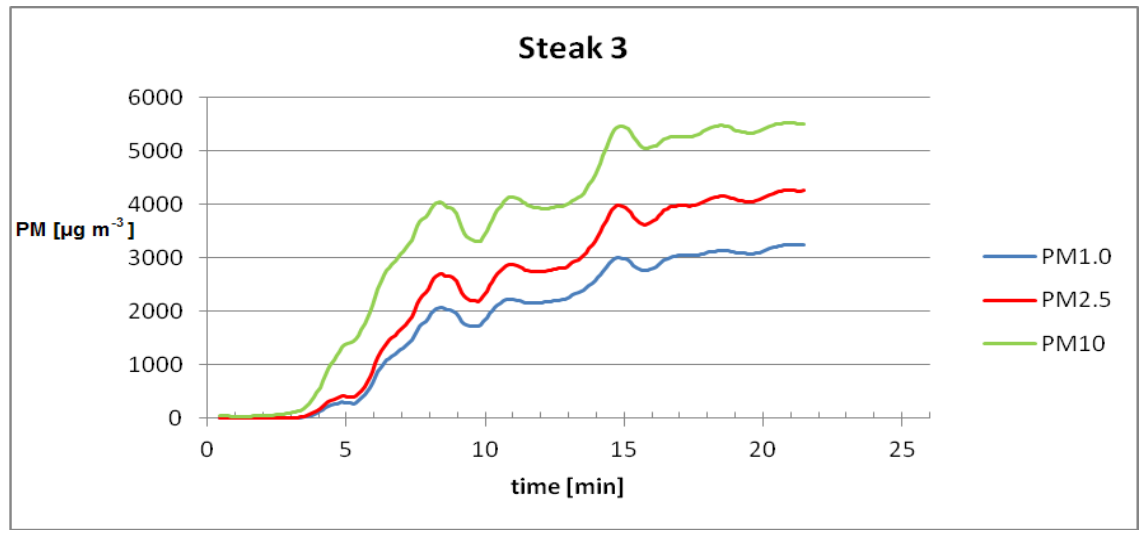

Figure 3: PM concentration during the cooking of "Steak 3".

From the figures above, it can be seen that the higher the thermal power, the higher the PM generation, especially regarding the finest particles $\left(\mathrm{PM}_{1.0}\right.$ and $\mathrm{PM}_{2.5}$ ).

Some considerations are needed for the peak concentrations of $\mathrm{PM}_{10}$. It is clear that those values are significant, since they can reach even $6,000 \mu \mathrm{g} \mathrm{m}^{-3}$ for a few minutes. The typical $\mathrm{PM}_{10}$ daily limit, according to the air quality guidelines, is two orders of magnitude smaller. However, if we compare the peak values with the permissible exposure limit (PEL) set by the Occupational Safety and Health Administration in the USA for short time exposure $\left(5,000 \mu \mathrm{g} \mathrm{m}^{-3}\right.$ for an averaging period of 8 hour), beef-steak cooking seems to be not critical. From another point of view, such high peak values can cause problems to asthmatic people. Efficient ventilation is then compulsory for keeping PM concentrations under acceptable values.

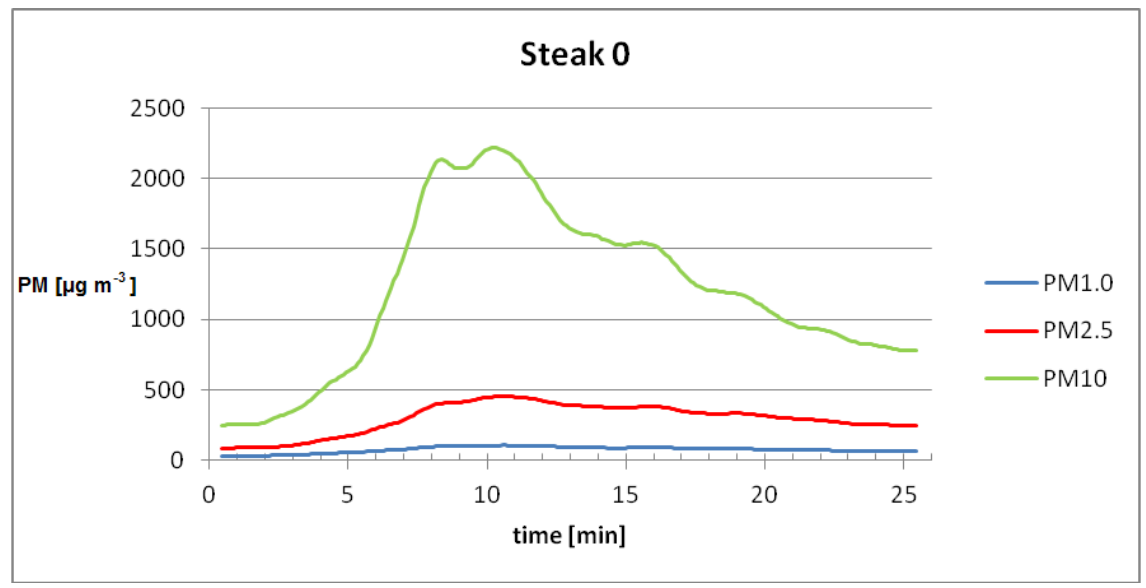

Figure 4: $\quad$ PM concentration during the cooking of "Steak 0". 
"Steak 0" [25] was cooked using a cooker with a thermal power similar to the one used for "Steak 2", in a different room. In this case the kitchen had a ventilation fan for gas extraction. The results are reported in Figure 4: the peak values for $\mathrm{PM}_{10}$ were similar in the two cases, but the advantages of ventilation compared to filtration are clear: in the "Steak 0" case the extraction of exhausted gas allowed a quick decrease of PM concentrations after cooking.

In Table 1 the indoor and outdoor average concentrations are reported. The indoor concentrations were monitored until the window opening. Then, the outdoor concentrations were monitored for 1 hour. Outdoor values were confirmed also from the fixed stations managed by the local environmental protection agency. Taking into account the values from Table 1, it can be noticed that indoor PM concentration before cooking and outdoor PM concentration did not influence PM concentrations during steak cooking.

Table 1: $\quad$ PM measurements.

\begin{tabular}{|c|c|c|c|c|c|}
\hline & Unit & Steak 0 & Steak 1 & Steak 2 & Steak 3 \\
\hline Thermal power & $\mathrm{kW}$ & - & 1.65 & 2.3 & 3 \\
\hline Lasting of the run & $\mathrm{min}$ & 25 & 26 & 26 & 22 \\
\hline Cooking time & $\mathrm{min}$ & 5 & 7 & 6 & 5 \\
\hline Average $\mathrm{PM}_{1.0}$ & $\mu \mathrm{g} \mathrm{m}^{-3}$ & 73 & 371 & 543 & 1826 \\
\hline Average $\mathrm{PM}_{2.5}$ & $\mu \mathrm{g} \mathrm{m}^{-3}$ & 291 & 521 & 725 & 2383 \\
\hline Average $\mathrm{PM}_{10}$ & $\mu \mathrm{g} \mathrm{m}^{-3}$ & 1180 & 1118 & 1348 & 3413 \\
\hline $\mathrm{PM}_{1.0} / \mathrm{PM}_{10}$ & - & $6 \%$ & $33 \%$ & $40 \%$ & $53 \%$ \\
\hline $\mathrm{PM}_{2.5} / \mathrm{PM}_{10}$ & - & $25 \%$ & $47 \%$ & $54 \%$ & $70 \%$ \\
\hline $\mathrm{PM}_{1.0}$ outdoor & $\mu \mathrm{g} \mathrm{m}^{-3}$ & 10 & 6 & 10 & 4 \\
\hline $\mathrm{PM}_{2.5}$ outdoor & $\mu \mathrm{g} \mathrm{m}^{-3}$ & 11 & 7 & 11 & 6 \\
\hline
\end{tabular}

Excluding "Steak 0", the higher was the thermal power, the higher was PM production in finest fractions. This can be seen also from Figure 5, where the PM concentrations are reported taking into account the 16 different granulometric classes from 0.3 to $>20 \mu \mathrm{m}$. $\mathrm{PM}_{1.0}$ represents $33 \%$ of $\mathrm{PM}_{10}$ concentration during "Steak 1" cooking and 53\% during "Steak 3" cooking. $\mathrm{PM}_{2.5}$ represents the $47 \%$ of $\mathrm{PM}_{10}$ concentration during "Steak 1" cooking and 70\% during "Steak 3" cooking. The increase in $\mathrm{PM}_{2.5}$ and $\mathrm{PM}_{10}$ concentration is connected with the increase in $\mathrm{PM}_{1.0}$ concentration.

Data from the three presented runs have been used also to obtain the "logradius" distributions, as shown in Figure 6, where:

$x$-axis reports the average diameter of the class (expressed in $\mu \mathrm{m}$ and on logarithmic scale);

$y$-axis reports the mass variation of the class (referred to the logarithm of the diameter itself). 


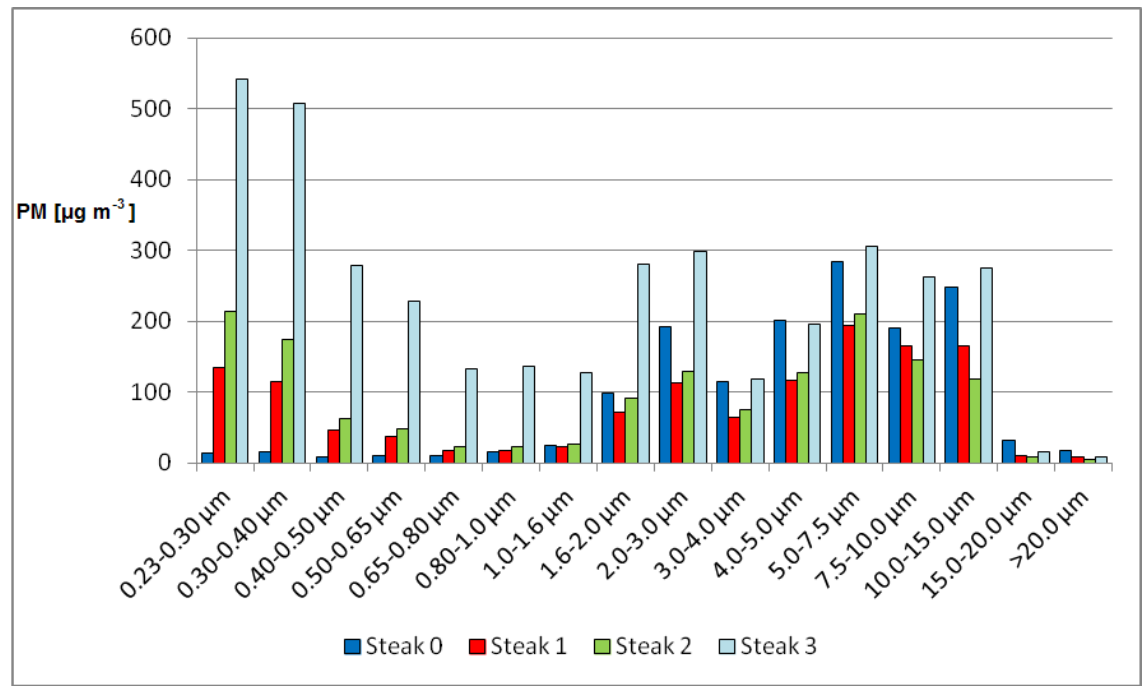

Figure 5: $\mathrm{PM}$ concentrations taking into account the here considered 16 granulometric classes.

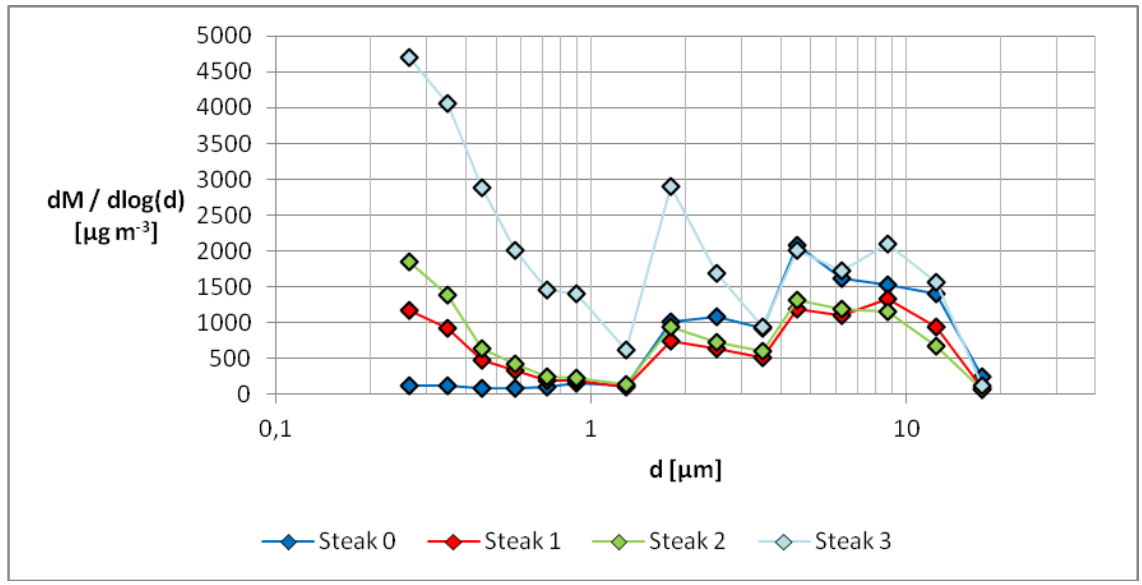

Figure 6: Log-radius curves.

From the analysis of the log-radius curves, it is clear that an increase of the thermal power for beef-steak cooking causes an increase of the particles with the finest granulometry. The curves referred to "Steak 1", "Steak 2" and "Steak 3" present the same trend: a high particle concentration for the lower classes $\left(D_{p}<0.4 \mu \mathrm{m}\right)$, a second peak around particles with $D_{p}$ in the range $2-3 \mu \mathrm{m}$ and a third peak for particles with $D_{p}$ in the range $4-10 \mu \mathrm{m}$. The curves show a quick decrease for higher diameters. 


\section{Conclusions}

The thermal power of cookers can influence PM emission during beef-steak cooking. Using the most powerful cooker, $\mathrm{PM}_{10}$ production resulted 3 times higher than using the smaller one. In particular, this increase is connected with a significant generation of $\mathrm{PM}_{1.0}$. The reached values were related to short-time exposures but an optimization of kitchen ventilation is anyway compulsory. These parameters (power and ventilation) should be taken into account carefully when the role of kitchen rooms must be analyzed and quantified in human exposure studies. Considering that such high PM concentrations were achieved by means of natural gas cookers, higher concentrations would be expected if the cooking process were carried out by burning biomass. The variation of the domestic fuel and its effects on the indoor air quality represents a future step of this research. An additional step will concern the chemical characterization of the generated PM and the assessment of the health risk related to the exposure to these peaks of concentration.

\section{References}

[1] Li, C.S., Elemental composition of residential indoor $\mathrm{PM}_{10}$ in the urban atmosphere of Taipei. Atmospheric Environment, 28, pp. 3139-3144, 1994.

[2] Keary, J., Jennings, S.G., O’Connor, T.C., Mcmanus, B., Lee, M., PM 10 concentration measurements in Dublin city. Environmental Monitoring and Assessment, 52, pp. 3-18, 1998.

[3] Li, M., Mcdow, S.R., Tollerud, D.J., Mazurek, M.A., Seasonal abundance of organic molecular markers in urban particulate matter from Philadelphia, PA. Atmospheric Environment, 40, pp. 2260-2273, 2006.

[4] Efe, S.I., Efe, A.T., Spatial distribution of particulate matter $\left(\mathrm{PM}_{10}\right)$ in Warri metropolis, Nigeria. Environmentalist, 28, pp. 385-394, 2008.

[5] Toledo, V.E., De Almeida Júnior, P.B., Quiterio, S.L., Arbilla, G., Moreira, A., Escaleira V., Moreira, J.C., Evaluation of levels, sources and distribution of toxic elements in $\mathrm{PM}_{10}$ in a suburban industrial region, Rio de Janeiro, Brazil. Environmental Monitoring and Assessment, 139, pp. 4959, 2008.

[6] Huang, Q., Cheng, S., Li, J., Chen, D., Wang, H., Guo, X., Assessment of $\mathrm{PM}_{10}$ emission sources for priority regulation in urban air quality management using a new coupled MM5-CAMx-PSAT modeling approach. Environmental Engineering Science, 29, pp. 343-349, 2012.

[7] Vujic, B., Pavlovic, A., Vujic, G., Jevtic, D., Assessment of Concentration Levels of Particulate Matters ( $\mathrm{PM}_{10}$, TSP and BS) in the Area of Zrenjanin, Vojvodina, Serbia. Chemistry Magazine, 61, pp. 91-1007, 2010.

[8] Perrone, M.G., Larsen, B.R., Ferrero, L., Sangiorgi, G., De Gennaro, G., Udisti, R., Zangrando, R., Gambaro, A., Bolzacchini, E., Sources of high $\mathrm{PM}_{2.5}$ concentrations in Milan, Northern Italy: molecular marker data and CMB modelling. Science of the Total Environment, 414, pp. 343-355, 2012. 
[9] Toscano, G., Gambaro, A., Moret, I., Capodaglio, G., Turetta, C., Cescon, P., Trace metals in aerosol at Terra Nova Bay, Antarctica. Journal of Environmental Monitoring, 7, pp. 1275-1280, 2005.

[10] Rada, E.C., Ragazzi, M., Malloci, E., Levoglucosan as a tracer of wood combustion in an alpine region. Environmental Technology, 33, pp. 989994, 2012.

[11] Kousa, A., Oglesby, L., Koistinen, K., Künzli, N., Jantunen, M., Exposure chain of urban air $\mathrm{PM}_{2.5}$ - associations between ambient fixed site, residential outdoor, indoor, workplace and personal exposures in four European cities in the EXPOLIS-study. Atmospheric Environment, 36, pp. 3031-3039, 2002.

[12] Ciuta S., Schiavon, M., Chistè, A., Ragazzi, M., Rada, E.C., Tubino, M., Badea, A., Apostol, T., Role of feedstock transport in the balance of primary PM emissions in two case-studies: RMSW incineration vs. sintering. Scientific Bulletin, Serie D, Mechanical Engineering, 74(1), pp. 211-218, 2012.

[13] Contini, D., Gambaro, A., F. Belosi, F., De Pieri, S., Cairns, W., Donateo, A., Zanotto, E., Citron, M., The direct influence of ship traffic on atmospheric $\mathrm{PM}_{2.5}, \mathrm{PM}_{10}$ and PAHs in Venice. Journal of Environmental Management, 92, pp. 2119-2129, 2011.

[14] Torretta, V., Rada, E.C., Panaitescu, V., Apostol, T., Some considerations on particulate generated by traffic, Scientific Bulletin, Series D: Mechanical Engineering, 74(4), pp. 241-248, 2012.

[15] Toscano, G., Moret, I., Gambaro, A., Barbante, C., Capodaglio, G., Distribution and seasonal variability of trace elements in atmospheric particulate in the Venice Lagoon. Chemosphere, 85, pp. 1518-1524, 2011.

[16] Ragazzi, M., Rada, E.C., Multi-step approach for comparing the local air pollution contributions of conventional and innovative MSW thermochemical treatments, Chemosphere, 89(6), pp. 694-701, 2012.

[17] Wu, S., Feng, Q., Du, Y., Li, X., Artificial neural network models for daily $\mathrm{PM}_{10}$ air pollution index prediction in the urban area of Wuhan, China. Environmental Engineering Science, 28, pp. 357-363, 2011.

[18] Buonanno, G., Morawska, L., Stabile, L., Viola A., Exposure to particle number, surface area and PM concentrations in pizzerias. Atmospheric. Environment, 44, pp. 3963-3969, 2010.

[19] Wang, X., Bi, X., Sheng, G., Fu, J., Hospital indoor $\mathrm{PM}_{10} / \mathrm{PM}_{2.5}$ and associated trace elements in Guangzhou, China. Science of the Total Environment, 366, pp. 124-135, 2006.

[20] Lin, C.C. and Peng, C.K., Characterization of indoor $\mathrm{PM}_{10}, \mathrm{PM}_{2.5}$, and ultrafine particles in elementary school classrooms: A review. Environmental Engineering Science, 27, pp. 915-922, 2010.

[21] Chuang, H.C., Jones, T., BéruBé, K., Combustion particles emitted during church services: Implications for human respiratory health. Environment International, 40, pp. 137-142, 2012. 
[22] Kim, Y.S., Kim, J.T., Kim, I.W., Kim, J.C., Yoo, C., Multivariate monitoring and local interpretation of indoor air quality in Seoul's metro system. Environmental Engineering Science, 27, pp. 721-731, 2010.

[23] Massey, D., Kulshrestha, A., Masih, J., Taneja A., Seasonal trends of $\mathrm{PM}_{10}$, $\mathrm{PM}_{5.0}, \mathrm{PM}_{2.5} \& \mathrm{PM}_{1.0}$ in indoor and outdoor environments of residential homes located in North-Central India. Building and Environment, 47, pp. 223-231, 2012.

[24] Molnár, P., Gustafson, P., Johannesson, S., Boman, J., Barregård, L, Sällsten G., Domestic wood burning and $\mathrm{PM}_{2.5}$ trace elements: Personal exposures, indoor and outdoor levels. Atmospheric Environment, 39, pp. 2643-2653, 2005.

[25] Abdullahi, K.L., Delgado-Saborit, J.M., Harrison, R.M., Emissions and indoor concentrations of particulate matter and its specific chemical components from cooking: A review. Atmospheric. Environment, DOI: http://dx.doi.org/10.1016/j.bbr.2011.03.031, 2013 (in press)

[26] Rada, E.C., Ragazzi, M., Antolini, D., Malloci, E., Venturi, M., In-door air measurements of $\mathrm{PM}_{10}$ in different conditions. Proc. of the Int. Symp. on Environmental Science and Technology, Shanghai, China, vol. II, pp. 571577, 2009.

[27] Buonanno, G., Morawska, L., Stabile, L., Particle emission factor during cooking activities. Atmospheric. Environment, 43, pp. 3235-3242, 2009. 